\title{
Article \\ Does Symmetry Control Photocatalytic Activity of Titania-Based Photocatalysts?
}

\author{
Marcin Janczarek ${ }^{1,2, *}$, Zhishun Wei ${ }^{2,3}{ }^{\circledR}$, Tharishinny R. Mogan ${ }^{2}$, Lei Wang ${ }^{2,4}$, Kunlei Wang ${ }^{2,5}$, Akio Nitta ${ }^{2,4}$, \\ Bunsho Ohtani 2,4 (D) and Ewa Kowalska $2,4, *$ (D) \\ 1 Faculty of Chemical Technology, Institute of Chemical Technology and Engineering, \\ Poznan University of Technology, ul. Berdychowo 4, 60-965 Poznan, Poland \\ 2 Institute for Catalysis, Hokkaido University, Sapporo 001-0021, Japan; wei.zhishun@hbut.edu.cn (Z.W.); \\ rajamogan.t@cat.hokudai.ac.jp (T.R.M.); wang.lei@cat.hokudai.ac.jp (L.W.); kunlei@cat.hokudai.ac.jp (K.W.); \\ nitta.akio.xitik@showadenko.com (A.N.); ohtani@cat.hokudai.ac.jp (B.O.) \\ 3 Hubei Provincial Key Laboratory of Green Materials for Light Industry, Hubei University of Technology, \\ Wuhan 430068, China \\ 4 Graduate School of Environmental Science, Hokkaido University, Sapporo 060-0810, Japan \\ 5 Northwest Research Institute, Co., Ltd. of China Railway International Group, Lanzhou 730000, China \\ * Correspondence: marcin.janczarek@put.poznan.pl (M.J.); kowalska@cat.hokudai.ac.jp (E.K.)
}

check for

updates

Citation: Janczarek, M.; Wei, Z.; Mogan, T.R.; Wang, L.; Wang, K.; Nitta, A.; Ohtani, B.; Kowalska, E. Does Symmetry Control Photocatalytic Activity of Titania-Based Photocatalysts? Symmetry 2021, 13, 1682. https://doi.org/10.3390/ sym13091682

Academic Editors: Bozhidar Stefanov, İlknur Bayrak Pehlivan and Silvia Todorova

Received: 15 August 2021

Accepted: 9 September 2021

Published: 12 September 2021

Publisher's Note: MDPI stays neutral with regard to jurisdictional claims in published maps and institutional affiliations.

Copyright: (C) 2021 by the authors Licensee MDPI, Basel, Switzerland. This article is an open access article distributed under the terms and conditions of the Creative Commons Attribution (CC BY) license (https:// creativecommons.org/licenses/by/ $4.0 /)$
Abstract: Decahedral anatase particles (DAPs) have been prepared by the gas-phase method, characterized, and analyzed for property-governed photocatalytic activity. It has been found that depending on the reaction systems, different properties control the photocatalytic activity, that is, the particle aspect ratio, the density of electron traps and the morphology seem to be responsible for the efficiency of water oxidation, methanol dehydrogenation and oxidative decomposition of acetic acid, respectively. For the discussion on the dependence of the photocatalytic activity on the morphology and/or the symmetry other titania-based photocatalysts have also been analyzed, that is, octahedral anatase particles (OAP), commercial titania P25, inverse opal titania with and without incorporated gold NPs in void spaces and plasmonic photocatalysts (titania with deposits of gold). It has been concluded that though the morphology governs photocatalytic activity, the symmetry (despite its importance in many cases) rather does not control the photocatalytic performance.

Keywords: heterogeneous photocatalysis; faceted anatase; decahedral anatase; octahedral anatase; morphology; symmetry; photocatalytic activity

\section{Introduction}

Recently, heterogeneous photocatalysts have been extensively explored as it has been thought that well-designed photocatalysts might efficiently convert solar energy into electricity and fuels, as well as purify water and the whole environment via "green" processes using only sunlight [1-7]. Accordingly, there is a huge interest in the design and the architecture of photoactive materials. Various reports on the morphology importance have already been published, suggesting that specific structures, for example, nanowires, nanotubes, opals and inverse opals, and faceted particles, result in enhanced photocatalytic performance [8-12]. Many papers have shown that morphology is a key factor for photocatalytic activity [11,13-18]. For example, an intrinsic property of decahedral anatase particles (DAPs) allows the separation of charge carriers inside those crystals as photo-generated electrons and holes migrate to different facets ( $\{101\}$ and $\{001\}$, respectively) [17]. However, direct proof that only morphology controls photocatalytic activity is very difficult to be obtained as, with any change in the synthesis conditions, all properties (not only morphology) are changing simultaneously. Finally, it has been directly proven that octahedral anatase particles (OAPs), prepared by ultrasonication (US)-assisted hydrothermal (HT) reaction, govern photocatalytic activity [19]. In this study, three series of samples have been prepared by changing synthesis conditions, that is, US duration, HT duration and HT 
temperature. Although all properties of samples prepared under different HT conditions differ significantly, a series of samples prepared under different durations of US is characterized by almost the same physical properties (crystallinity, specific surface area, crystallite size) but having different photocatalytic activities. Accordingly, it has been shown that those samples (differed only by morphology, that is, the content of faceted particles in the product) show morphology-governed activity since with an increase in the number of OAPs the activity increases. Based on photoacoustic spectroscopy (PAS) and time-resolved microwave conductivity (TRMC), it has been proposed that morphology-controlled activity in OAPs results from preferential distribution of shallow than deep electron traps (ETs), causing higher mobility and longer-lifetime of electrons [18].

Summarizing, it has been proven that OAP morphology (bipyramid) governs photocatalytic activity, and there are many reports showing that various photocatalysts with well-organized morphology exhibit higher photocatalytic activity than irregularly shaped materials $[15,20-26]$. In contrast to "the morphology", "the symmetry" has been mentioned very rarely in the studies on heterogeneous photocatalysis. It looks that almost nobody considers symmetry and/or asymmetry as an important factor for photocatalytic reactions. There are only several studies using the term "symmetry/asymmetry", for example, nine papers found in Web of Science for "symmetry" and "heterogeneous photocatalysis" (8 July 2021). However, even among these papers, symmetry mainly concerns organic molecules rather than photocatalyst structure, for example, stearic acid crystal (B-polymorph) deposited onto anatase/amorphous titania film [27]. Some reports do not discuss at all symmetry-activity correlation, presenting only other aspects, such as: (i) preparation of materials with broken symmetry, for example, from core-shell to coresatellite (gold@silica) [28], (ii) characterization of photocatalyst, for example, hexagonal p6mm symmetry for mesoporous graphene-titania/silica composite [29], (iii) determination of the shape of nanoparticles based on measurements of single-electron quantum levels for nanoparticles (NPs) of high symmetry: cube and sphere [30]. Interestingly, Zhang et al. have discussed the symmetry of the unit cell for $\mathrm{KNbO}_{3}$ by DFT calculations [31]. They have concluded that facile electron excitation and transfer (correlating with photocatalytic activity) is achieved for cubic $\mathrm{KNbO}_{3}$ with the highest symmetry in comparison to tetragonal and orthorhombic structures. However, though the structural symmetry of orthorhombic $\mathrm{KNbO}_{3}$ is lower than that of tetragonal $\mathrm{KNbO}_{3}$, it presents a better performance, probably due to better morphology, that is, the exposed facets and the associated electronic structure. In contrast, King et al. have found that structure distortions lowering the symmetry have an influence on the photocatalytic performance, for example, for $\mathrm{PbTa}_{4} \mathrm{O}_{11}$ with an out-of-plane distortion of the $\mathrm{d}^{0}$ transition metal cation, an internal electric dipole can facilitate the separation of charge carriers (electron/hole), hindering the recombination and back-reaction [32]. Finally, Huang et al. have reviewed synthesis methods for symmetry-breaking in multicomponent NPs, concluding that NPs with broken symmetry could be beneficial for various photocatalytic and electrocatalytic reactions resulting from: (i) arrangement of one-direction of charge migration, (ii) spatial separation of domains (prevention of reverse reactions), and (iii) synergism at the interface of different domains [33].

Considering the lack of information on "the symmetry" importance (or not) in heterogeneous photocatalysis, this paper aims to discuss "the symmetry" in correlation with photocatalytic activity and morphology. First, we have focused on highly active faceted samples, then, other bare and modified titania photocatalysts have been presented to check if and how (a)symmetry and/or morphology might influence their performance.

\section{Materials and Methods}

DAPs were prepared by using a gas-phase experimental set-up, described previously in detail [20]. In brief, $\mathrm{TiCl}_{4}(7.5 \mathrm{~mL})$ was continuously supplied to a vaporizer vessel by an automatic syringe feeder with a specified flow rate $\left(0.8-2.2 \mathrm{~mL} \mathrm{~h}^{-1}\right)$. Simultaneously, argon (40-100 mL min ${ }^{-1}$ ) was passed through the vaporizer as the carrier gas for $\mathrm{TiCl}_{4}$ 
vapors that were transferred to a quartz reaction tube $(45 \mathrm{~cm} \times 3.8 \mathrm{~cm})$ where oxygen gas was introduced. The narrow reaction zone $(3 \mathrm{~cm}$ width) located in the center of the reaction (500-1000 $\mathrm{mL} \mathrm{min}^{-1}$ ) tube was heated by an infrared furnace $(1373 \mathrm{~K})$. The resultant particles were collected in a corn-shape glass-fiber filter and subsequently washed thoroughly with water to remove residual chlorine, and finally freeze-dried under vacuum. DAP-containing samples were fabricated according to adjustment of resultant parameter: line speed ratio (LSR) with keeping $\mathrm{TiCl}_{4} / \mathrm{O}_{2}$ molar ratio unchanged. LSR of reactant gases was calculated from Equation (1):

$$
L S R=\frac{U_{\mathrm{TiCl}_{4}}+U_{A r}}{U_{\mathrm{O}_{2}}}
$$

where $U_{T_{i C l} l_{4}}, U_{A r}$, and $U_{O_{2}}$ are line speeds of $\mathrm{TiCl}_{4}$ vapor, $\mathrm{Ar}$, and $\mathrm{O}_{2}$, respectively [11].

The morphology of the obtained DAPs - particle shape distribution (PSD)-was evaluated by visual analysis with a field emission scanning electron microscopy (FE-SEM; JEOL JSM-7400F). To perform a shape recognition of particles, the following classification was proposed (Figure 1): (i) "DAP"—particles with decahedral shape without visual defects, clearly recognizable from SEM image. The probability of the occurrence of pure decahedral structure is $50 \%$ since only one side is observed; (ii) "semi-DAP" — particles with decahedral shape but simultaneously containing noticeable defects (e.g., mounds located on the facets), deformed decahedral particles and aggregates, which were counted as one particle; (iii) "other shape" — particles with a shape different than decahedron (regular or irregular). The exemplary images of particles are shown in Figure 1.
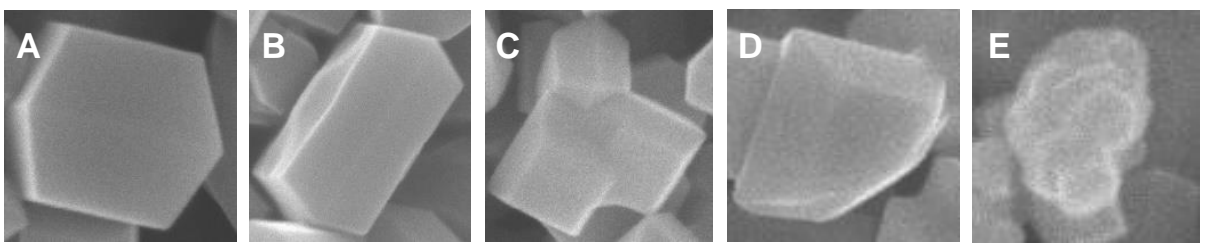

Figure 1. SEM images of particles classified to the different shape categories: (A)_ "DAP"; (B)—“semi-DAP (mounds)"; (C)—“semi-DAP (aggregates)"; (D)—“semi-DAP (other)"; (E)— "other shape".

Evaluation of electron traps (ETs; lattice defects) density was performed by the measurement of electron accumulation by photoirradiation under deaerated conditions in the presence of methanol as an electron donor (hole scavenger) by double-beam photoacoustic spectroscopy [34,35]. Calibration of the photoacoustic signal to the absolute density of electron accumulation in the sample was carried out at $625 \mathrm{~nm}$ under photoexcitation at $365 \mathrm{~nm}$.

BET specific surface area (SSA) was measured by Yuasa Ionics Autosorb 6AG surface area and pore size analyzer. SSA was calculated from nitrogen absorption at $77 \mathrm{~K}$ using the Brunauer-Emmett-Teller equation.

Primary particle size (PPS; crystallite size), phase content, and particle aspect ratio were determined by $\mathrm{X}$-ray diffraction method using $\mathrm{Cu}-\mathrm{K} \alpha$ radiation by a Rigaku SmartLab. The crystallite size was calculated by Scherrer equation using corrected full width at half maximum (FWHM) of the most intense XRD peaks of anatase at ca. $25.3 \mathrm{deg}$. As a constant in the Scherrer equation, 0.891 was used. Crystallite size was estimated by the HalderWagner method. The crystallinity of a sample was calculated by the internal standard method, in which highly crystalline nickel oxide (NiO) was used as the standard, by mixing titania sample $(80 \mathrm{wt} \%)$ and $\mathrm{NiO}(20 \mathrm{wt} \%)$ in an agate mortar before XRD analysis. The applied method is based on the assumption that Rietveld analysis ensures the weight fraction of each phase among total crystalline components, and the weight fraction of $\mathrm{NiO}$ is overestimated if a sample contains an amorphous content. Particle aspect ratio 
(d001/d101) was calculated by the quotient of crystallite sizes related to anatase XRD peaks (004) and (101).

Photocatalytic activity tests of DAPs were performed in three reaction systems: (i) oxidative decomposition of acetic acid $\left(\mathrm{CO}_{2}\right.$ system; Equation (2); (ii) dehydrogenation of methanol $(\mathrm{MeOH})$ with in situ platinum photodeposition $(2 \mathrm{wt} \%$, from hexachloroplatinic acid) in deaerated conditions $\left(\mathrm{H}_{2}\right.$ system; Equation (3) and (iii) oxygen liberation from water in the presence of silver nitrate as a sacrificial electron scavenger $\left(\mathrm{O}_{2}\right.$ system; Equation (4). The enumerated reaction systems are characterized by the following stoichiometries:

$$
\begin{gathered}
\mathrm{CH}_{3} \mathrm{COOH}+2 \mathrm{O}_{2} \rightarrow 2 \mathrm{CO}_{2}+2 \mathrm{H}_{2} \mathrm{O}, \\
\mathrm{CH}_{3} \mathrm{OH} \rightarrow \mathrm{HCHO}+\mathrm{H}_{2}, \\
4 \mathrm{Ag}^{+}+2 \mathrm{H}_{2} \mathrm{O} \rightarrow 4 \mathrm{Ag}+\mathrm{O}_{2}+4 \mathrm{H}^{+},
\end{gathered}
$$

In the case of system (i), molecular oxygen from air is an electron acceptor, the photogenerated hole oxidizes acetic acid finally into $\mathrm{CO}_{2}$; (ii) at the beginning of the irradiation, hexachloroplatinic acid is reduced to platinum particles by photoexcited electrons and deposited on the surface of photocatalyst. The presence of platinum is necessary to induce $\mathrm{H}_{2}$ evolution. MeOH plays in this system the role of an electron donor; (iii) Ag-metal deposition occurs via reduction of the adsorbed $\mathrm{Ag}^{+}$ion by an electron generated simultaneously with a hole. Oxygen is liberated as a consequence of the oxidative decomposition of water by photogenerated holes. Each photocatalyst $(50 \mathrm{mg})$ was put into a test tube with a volume of ca. $35 \mathrm{~mL}$ and suspended in an aqueous solution (5.0 mL) containing $5.0 \mathrm{vol} \%$ acetic acid (i), $50 \mathrm{vol} \% \mathrm{MeOH}$ (ii), or $50 \mathrm{mmol} \mathrm{L}^{-1}$ silver nitrate (iii). In the case of system (ii), hydrogen hexachloroplatinate(IV) $(\mathrm{H} 2 \mathrm{PtCl} \cdot 6 \mathrm{H} 2 \mathrm{O})$ was added to reach $2.0 \mathrm{wt} \%$ $\mathrm{Pt}$ loading. The suspensions of (ii) and (iii) were bubbled with argon before irradiation to remove oxygen. Test tubes were sealed with rubber septa and irradiated with UV/Vis light $(\lambda>290 \mathrm{~nm}$ ) using a $400 \mathrm{~W}$ high-pressure mercury lamp (Eiko-sha) with magnetic stirring at $1000 \mathrm{rpm}$. The reaction temperature was kept at $25^{\circ} \mathrm{C}$ using a thermostated water bath. To analyze the progress of reactions, the amount of $\mathrm{CO}_{2}(\mathrm{i}), \mathrm{H}_{2}$ (ii), and $\mathrm{O}_{2}$ (iii) were measured using a TCD gas chromatograph (Shimadzu GC-8A). The resultant molar amount was calibrated considering the increase of the pressure in the test tube by the increase of the gas-phase molecules.

For the reactions (i) and (ii) a rate of linear increase in product yield was applied for the evaluation of the photocatalytic activity. In the case of the $\mathrm{O}_{2}$ system, photocatalytic activity was estimated from the initial rate of $\mathrm{O}_{2}$ evolution because the rate of $\mathrm{O}_{2}$ liberation tends to decrease with irradiation time in connection with the fact that $\mathrm{pH}$ value decreases by stoichiometric proton liberation, resulting in depletion of adsorption of silver cations. At the same time, the photocatalytic activity of titania commercial photocatalysts-P25 was measured to eliminate the possible influence of lamp aging (and any other changes during photocatalytic activity tests), and data have been shown as "relative" in respect to those obtained by P25 (defined as "relative photocatalytic activity"). All photocatalytic activity tests were performed three times.

\section{Results}

\subsection{Preparation Conditions and Properties of DAPs}

The conditions during the preparation of DAP-containing samples were slightly altered to maintain similar structural/physical properties such as crystallite size, BET specific surface area (SSA), phase content, and crystallinity. The preparation of DAPs by the proposed gas-phase method is determined by three main parameters [11]: (a) concentration of $\mathrm{TiCl}_{4}$ vapors in the reaction zone (adjusted to $0.9 \mathrm{vol} \%$ ), (b) $L S R$ between argon and $\mathrm{TiCl}_{4(\mathrm{~g})}$ mixture and $\mathrm{O}_{2}$ gas streams, and (c) furnace temperature (1373 K). Only LSR was changed to obtain DAPs with different particle morphology and similar physical properties. The samples containing DAPs taken to the analysis and details of preparation conditions are presented in Table 1. 
Pertaining to resultant structural/physical properties of prepared DAP samples, the values of PPS, SSA, anatase content, and crystallinity are in the range of $64-69 \mathrm{~nm}$, $14.6-16.2 \mathrm{~m}^{2} \mathrm{~g}^{-1}, 96.3-97.6 \%$, and $92.4-93.8 \%$, respectively, as shown in Table 2 . The reported differences are negligible for performing the study of the correlation between particle morphology/symmetry and photocatalytic activity.

Table 1. Controlled and resultant parameters for gas-phase preparation of DAPs.

\begin{tabular}{|c|c|c|c|c|}
\hline Sample & $\begin{array}{l}L S R \\
\text { (a.u.) }\end{array}$ & $\begin{array}{c}\mathrm{TiCl}_{4(\mathrm{~g})} \text { Flow Rate } \\
\left(\mathrm{mL} \mathrm{h} \mathrm{h}^{-1}\right)\end{array}$ & $\begin{array}{l}\mathrm{O}_{2(\mathrm{~g})} \text { Flow Rate } \\
\left.\text { (mL min }{ }^{-1}\right)\end{array}$ & 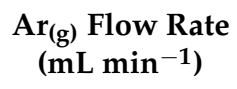 \\
\hline DAP-1 & 0.049 & 1.5 & 1000 & 40 \\
\hline DAP-2 & 0.059 & 2.2 & 1500 & 75 \\
\hline DAP-3 & 0.074 & 1.5 & 1000 & 65 \\
\hline DAP-4 & 0.084 & 1.5 & 1000 & 75 \\
\hline DAP-5 & 0.096 & 1.5 & 1000 & 87 \\
\hline DAP-6 & 0.109 & 1.5 & 1000 & 100 \\
\hline DAP-7 & 0.125 & 1.0 & 650 & 75 \\
\hline DAP-8 & 0.160 & 0.8 & 500 & 75 \\
\hline
\end{tabular}

Table 2. Physical properties of DAPs' samples.

\begin{tabular}{cccccc}
\hline Sample & SSA $\mathbf{( m}^{\mathbf{2}} \mathbf{g}^{-\mathbf{1})}$ & PPS $(\mathbf{n m})$ & $\begin{array}{c}\text { Anatase } \\
\text { Content } \mathbf{( \% )}\end{array}$ & $\begin{array}{c}\text { Rutile } \\
\text { Content } \mathbf{( \% )}\end{array}$ & $\begin{array}{c}\text { Crystallinity } \\
\mathbf{( \% )}\end{array}$ \\
\hline DAP-1 & 14.6 & 64 & 96.3 & 3.7 & 93.8 \\
DAP-2 & 14.7 & 64 & 96.9 & 3.1 & 92.5 \\
DAP-3 & 15.2 & 67 & 97.7 & 2.3 & 93.3 \\
DAP-4 & 16.0 & 67 & 97.8 & 2.2 & 93.2 \\
DAP-5 & 16.3 & 66 & 97.6 & 2.4 & 94.1 \\
DAP-6 & 14.7 & 69 & 96.9 & 3.1 & 92.4 \\
DAP-7 & 16.0 & 64 & 97.8 & 2.2 & 92.9 \\
DAP-8 & 16.2 & 64 & 97.6 & 2.4 & 93.5 \\
\hline
\end{tabular}

Table 3 contains the data of particle shape distribution (PSD) analysis that was performed according to the categories defined in Section 2. The change of LSR caused significant changes in DAP content. Generally, lower values of $L S R$ are not favorable for the quality of DAPs (samples DAP1-DAP3). The number of particles with other shapes has not been a significant parameter for further analysis because the values are at similar levels of $2.0-7.7 \%$. If only the samples prepared with different Ar flow rates are taken for the analysis (samples DAP-1, DAP-3, DAP-4, DAP-5, DAP-6), the highest DAP content is noted for $\mathrm{Q}_{\mathrm{Ar}}=75 \mathrm{~mL} \mathrm{~min}^{-1}$ (sample DAP-4). For the samples where the $\mathrm{Q}_{\mathrm{TiCl}}$ (l) and $\mathrm{Q}_{\mathrm{O} 2}$ have been changed simultaneously, the highest value of DAP content is observed for $\mathrm{Q}_{\mathrm{TiCl} 4(\mathrm{l})}=1.5 \mathrm{~mL} \mathrm{~h}^{-1}$ and $\mathrm{Q}_{\mathrm{O} 2}=1000 \mathrm{~mL} \mathrm{~min}^{-1}$ (sample DAP-4). These conditions correspond with the LSR of 0.084 .

Table 3. PSD of samples containing DAPs and particle aspect ratios of DAPs.

\begin{tabular}{lccccc}
\hline & \multicolumn{5}{c}{ Particle Shape Distribution * (\%) } \\
\cline { 2 - 5 } Sample & \multirow{2}{*}{$\begin{array}{c}\text { DAP (A) } \\
\text { Content }\end{array}$} & \multicolumn{3}{c}{ Semi-DAP Content } & \multirow{2}{*}{ Other (E) } \\
\cline { 2 - 5 } & $38.6 \pm 5.5$ & $55.3 \pm 0.8$ & $31.6 \pm 13.4$ & $3.3 \pm 1.3$ & $6.2 \pm 5.0$ \\
\hline DAP-1 & $45.9 \pm 11.0$ & $46.1 \pm 7.1$ & $16.1 \pm 1.7$ & $9.4 \pm 4.1$ & $7.7 \pm 4.4$ \\
DAP-2 & $44.5 \pm 6.3$ & $50.8 \pm 6.1$ & $24.6 \pm 2.6$ & $9.2 \pm 3.1$ & $4.7 \pm 1.8$ \\
DAP-3 & $77.0 \pm 4.2$ & $21.0 \pm 6.8$ & $8.2 \pm 1.7$ & $2.6 \pm 1.5$ & $2.0 \pm 2.7$ \\
DAP-4 & $54.5 \pm 9.9$ & $39.4 \pm 6.4$ & $22.7 \pm 5.9$ & $5.2 \pm 0.0$ & $6.1 \pm 3.1$ \\
DAP-5 & $46.2 \pm 9.7$ & $48.7 \pm 3.5$ & $21.5 \pm 2.9$ & $6.9 \pm 5.3$ & $5.0 \pm 7.1$ \\
DAP-6 & $68.8 \pm 4.4$ & $28.8 \pm 4.5$ & $12.5 \pm 1.8$ & $3.2 \pm 3.2$ & $2.4 \pm 1.4$ \\
DAP-7 & $62.5 \pm 5.6$ & $33.7 \pm 3.0$ & $17.7 \pm 2.8$ & $1.5 \pm 0.7$ & $3.8 \pm 2.7$ \\
DAP-8 & &
\end{tabular}

${ }^{*}$ Precision of particle shape distribution was calculated for a $95 \%$ confidence coefficient. The letters (A, B, C and E) correspond with the SEM images presented in Figure 1. 


\subsection{Particle Aspect Ratio (PAR) and Photocatalytic Activity}

At first, particle aspect ratio (PAR) was analyzed, according to the interpretation shown in Figure 2. In brief, lower PAR means higher and lower content of $\{001\}$ and $\{101\}$, respectively. The range of the content of $\{001\}$ facets for all samples reaches similar values of $21-24 \%$.

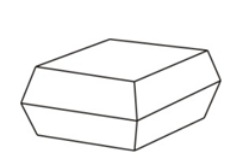

Low aspect ratio

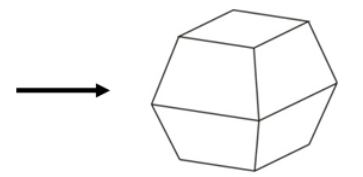

High aspect ratio

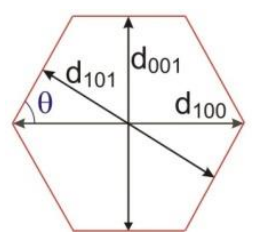

Figure 2. The scheme of PAR estimation.

The possible correlation between PAR and photocatalytic activities was investigated, and obtained data are shown in Figure 3. It is clear that the correlation could be only observed in the case of the $\mathrm{O}_{2}$ system, that is, water oxidation. In contrast, there is no correlation for the $\mathrm{H}_{2}$ system (dehydrogenation of methanol in the presence of in-situ Pt deposition), and only the optimum value of PAR between 0.90 and 0.92 was found for the $\mathrm{CO}_{2}$ system (oxidative decomposition of acetic acid). For oxygen evolution, the larger the PAR is (larger content of $\{101\}$ ), the higher is the level of photocatalytic activity. It should be pointed out that during water oxidation, photogenerated electrons are scavenged by in situ deposited silver (Equation (4). Interestingly, deposition of silver occurs selectively on $\{101\}$ facets, as shown in Figure 4a,b, which is consistent with previous reports [36]. Accordingly, it might be concluded that larger PAR, and thus larger content of surface with silver deposits, is responsible for higher photocatalytic activity. Moreover, it should be mentioned that it has been reported that the co-existence of $\{001\}$ facet is important for the separation of reactive sites for reduction and oxidation, that is, $\{101\}$ and $\{001\}$, respectively [36-38].

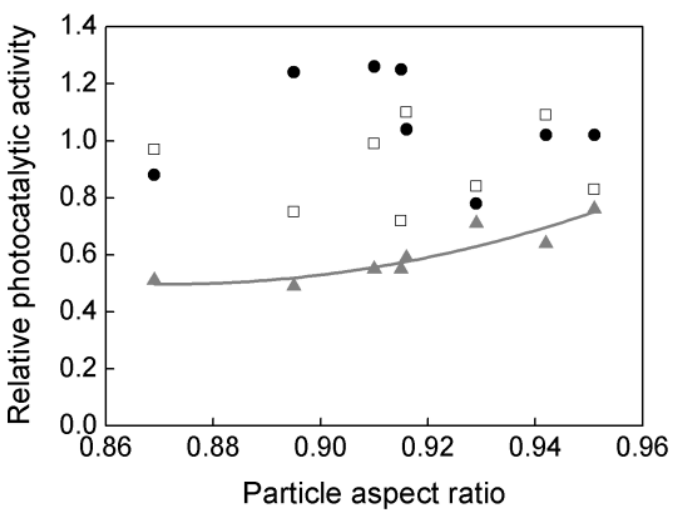

Figure 3. The dependence of photocatalytic activity in $\mathrm{CO}_{2}(\bullet), \mathrm{H}_{2}(\square)$, and $\mathrm{O}_{2}(\Delta)$ systems on the particle aspect ratio (PAR). Photocatalytic activities were standardized with reference to the photocatalytic activity of P25.

In the case of the $\mathrm{H}_{2}$ system, it is difficult to find any correlation between PAR and hydrogen evolution rate, as shown in Figure 3 (empty squares). There are two possible reasons for this observation, (i) the difference in the ratio of $\{001\}$ to $\{101\}$ is not large enough to influence any meaningful change in activity, or (ii) platinum (in contrast to silver) has also been deposited on \{001\} facets, as shown in Figure 4c. Similarly, Ohno et al., Amano et al., and Kobayashi et al. have shown that Pt NPs are deposited on both facets according to the order $\{101\}>\{001\}[37,39,40]$. 

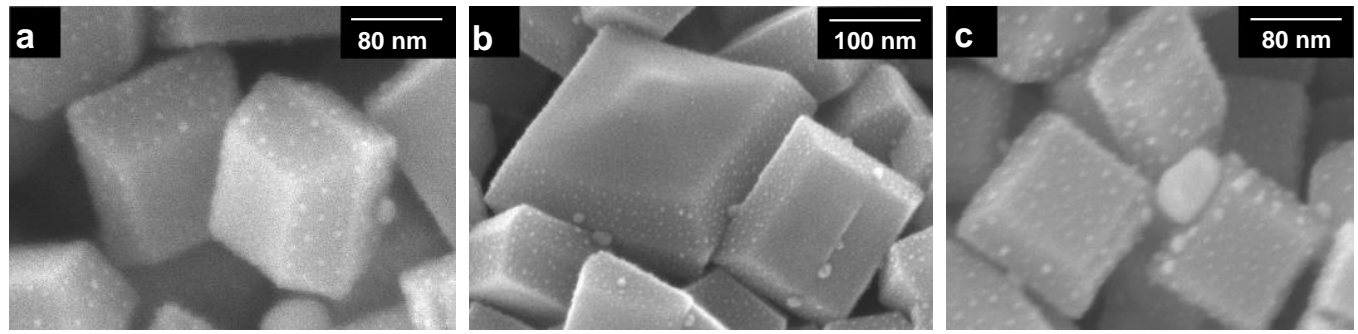

Figure 4. SEM images of DAPs with adsorbed: (a,b) Ag NPs and (c) Pt NPs.

\subsection{Density of Electron Traps (ETs) and Photocatalytic Activity}

As one of the main assumptions of DAPs preparation by the gas-phase method is to perform uniform and rapid heating at high temperatures, which enables homogeneous nucleation and subsequent growth to faceted single crystals with a low density of defects. It was found that the change in LSR influences the density of electron traps (ETs). One might expect that lower content of ETs (working as recombination centers of photogenerated charge carriers) results in activity increase. Indeed, a clear correlation could be found for the $\mathrm{H}_{2}$ system (Figure 5; open squares), where reaction rate decreases with an increase in the density of ETs. A similar tendency could be observed also for another reaction performed under aerobic conditions, that is, water oxidation, but with two different groups of samples (triangles in Figure 5). It is possible that ETs are especially detrimental for reactions performed in the absence of oxygen (working as electron scavengers). Buchalska et al. have confirmed that the main pathways of reduction and oxidation reactions are via direct reactions by photogenerated electrons and photogenerated holes, respectively [41]. Accordingly, it might be concluded that the photocatalytic performance in the absence of oxygen is governed by the low content of ETs. In contrast, it is difficult to find a clear correlation between photocatalytic activity in the $\mathrm{CO}_{2}$ system and neither density of ETs nor PAR. Therefore, it seems that other factors could be important, and thus morphology/symmetry of DAPs have been examined, as discussed in the next section.

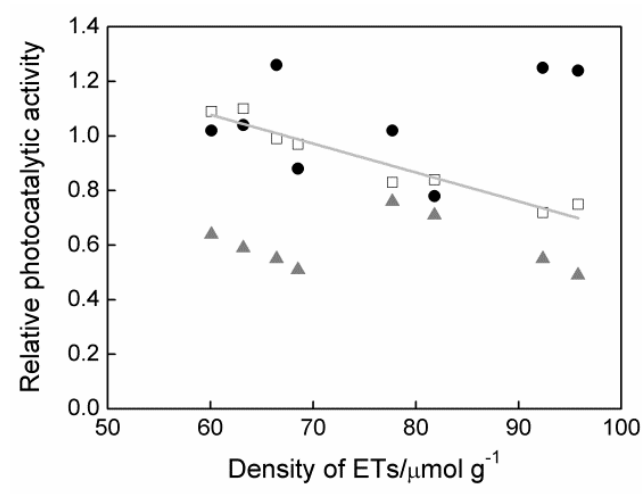

Figure 5. The dependence of photocatalytic activity in $\mathrm{CO}_{2}(\bullet), \mathrm{H}_{2}(\square)$, and $\mathrm{O}_{2}(\Delta)$ systems on density of ETs. Photocatalytic activities were standardized with reference to the photocatalytic activity of P25.

\subsection{Morphology/Symmetry and Photocatalytic Activity}

During the synthesis of DAPs, besides crystals with perfect morphology also deformed particles, as shown in Figure 1, could be formed. It might be considered that both DAPs without visual defects (Figure 1A) and semi-DAP with mounds (Figure 1B) could be classified as particles with good symmetry. To exclude the influence of other parameters only DAP samples with almost the same surface properties were considered as has been shown in Table 2. The comparison of photocatalytic activity for different reactions systems in relation to the above-mentioned two symmetry parameters is shown in Figure 6. 
(a)

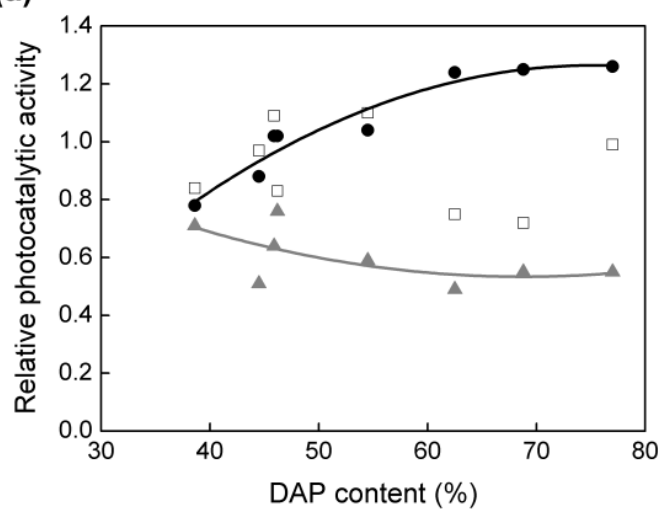

(b)

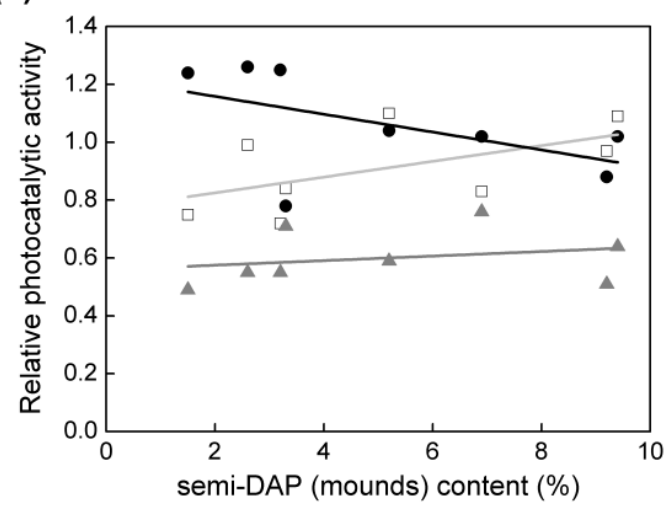

Figure 6. Correlation between photocatalytic activity $\left(\mathrm{CO}_{2}(\bullet), \mathrm{H}_{2}(\square)\right.$ and $\left.\mathrm{O}_{2}(\Delta)\right)$ and DAPs' morphology considering symmetric particles, that is, the content of: (a) DAPs and (b) semi-DAP (mounds). Photocatalytic activities were standardized with reference to the photocatalytic activity of P25.

Finally, the factor governing photocatalytic activity in the $\mathrm{CO}_{2}$ system was found, that is, morphology and/or symmetry of perfect crystals of DAPs, as clearly shown in Figure 6a. Interestingly, Figure $6 \mathrm{~b}$ indicates that DAP with mounds might be preferable for reactions occurring under anaerobic conditions. The discussion on morphology/symmetry governing photocatalysis activity of DAPs and other titania-based samples is presented in the next section.

\section{Discussion}

\subsection{Pristine Titania}

As shortly presented in the Introduction, the "symmetry" has been rarely used in the field of heterogeneous photocatalysis, whereas the "morphology" is very popular as proven by a huge number of scientific papers (more than 6700 papers found with "morphology" and "photocatalysis" words searched in Web of Science on 5 August 2021). Although it is clear that morphology is very important, being often a key factor of photocatalytic activity, the influence of symmetry and/or asymmetry is unclear. Accordingly, both aspects (symmetry and morphology) are discussed in this section.

First, two kinds of highly symmetric NPs are discussed, that is, faceted anatase particles, DAPs and OAPs (already presented in the Introduction). It should be pointed out that in the case of OAPs, there is only one type of facet, that is, $\{101\}$, and thus it means that $\{101\}$ is directly responsible for morphology-governed activity $[18,19]$. To check how morphology/symmetry might influence photocatalytic activity, OAPs have been postcalcined $(2 \mathrm{~h})$ in air at various temperatures (573-1173 K) and ground in an agate mortar [42]. Indeed, it has been confirmed that thermal treatment at high temperature $(>873 \mathrm{~K}$ ) results in the morphology change from OAPs to irregularly shaped NPs or aggregates (as shown in Figure 7), corresponding to an activity decrease. However, an activity increase was observed for samples treated at lower temperatures, that is, the highest activity was obtained for samples treated at $673 \mathrm{~K}$ and $873 \mathrm{~K}$ for oxidative decomposition of acetic acid $\left(\mathrm{CO}_{2}\right.$ system $)$ and dehydrogenation of methanol $\left(\mathrm{H}_{2}\right.$ system), respectively. Interestingly, thermal treatment at temperatures higher than $673 \mathrm{~K}$ has caused the deformation of OAPs (lower content of OAPs in the product and lower PAR). Moreover, the ground sample was the most active in the case of hydrogen generation, even though the perfect symmetry of OAP has been lost. Accordingly, it has been thought that although OAP morphology might govern activity due to preferential distribution of shallow than deep ETs [18,19], the change in morphology, resulting in some asymmetry might be beneficial for the overall activity, possibly due to the formation of a larger content of shallow ETs [42]. However, it is difficult to explain the data obtained for ground samples with the lowest intensity of TRMC signal (mobility of photogenerated electrons) and very high photocatalytic activity. 
Anyway, based on these data, it might be concluded that symmetry does not control the photocatalytic activity for OAPs.

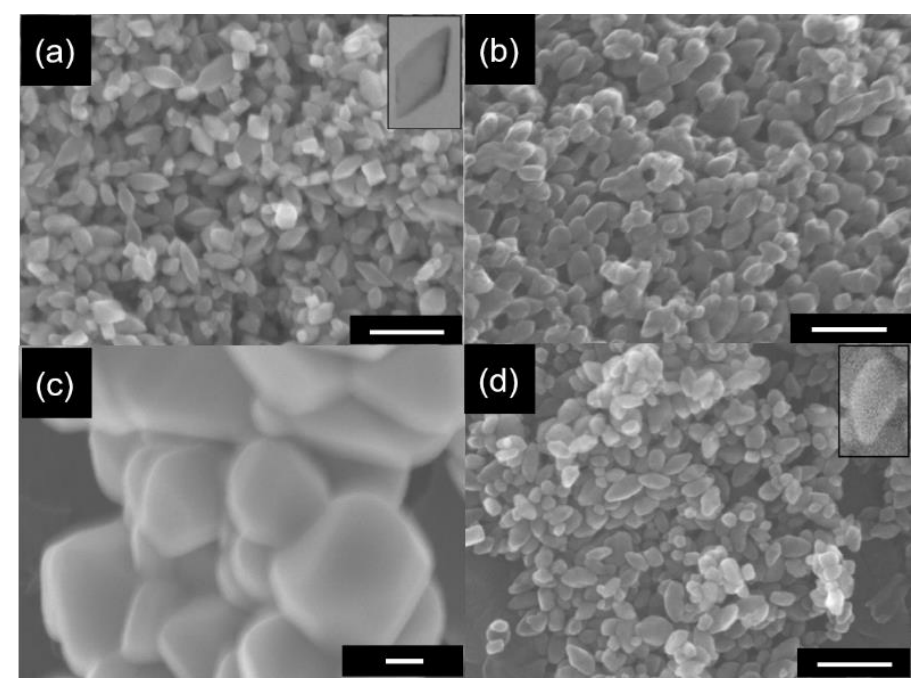

Figure 7. SEM images of: (a) original OAPs; (b) OAPs calcined at $873 \mathrm{~K}$; (c) OAPs calcined at $1173 \mathrm{H}$; (d) ground OAPs; scale bar: $100 \mathrm{~nm}$; representative image of single particle shown as insets in image (a,d). Adapted with permission from [42]. Copyright 2014, Creative Commons Attribution License.

Similarly, in the case of DAPs, it is difficult to find any direct correlation between symmetry and photocatalytic activity. Although it seems that in the case of the $\mathrm{CO}_{2}$ system, larger content of faceted particles (better morphology and at the same higher symmetry) results in higher photocatalytic activity (Figure 6a), the morphology/symmetry is not so important in the case of the other reactions. Additionally, considering other symmetric particles, for example, DAP aggregates (Figure 1C), it might be concluded that besides high symmetry their impact is detrimental for the activity (Figure 8). Therefore, in the case of the $\mathrm{CO}_{2}$ system, the morphology (the content of DAPs) rather than symmetry (since also aggregates are symmetric) seems to be more important for the photocatalytic activity, which is quite reasonable considering intrinsic properties of DAPs, that is, electron and hole transfer to $\{101\}$ and $\{001\}$ facets, respectively, and thus hindering of surface reactions by DAPs' aggregation.

(a)

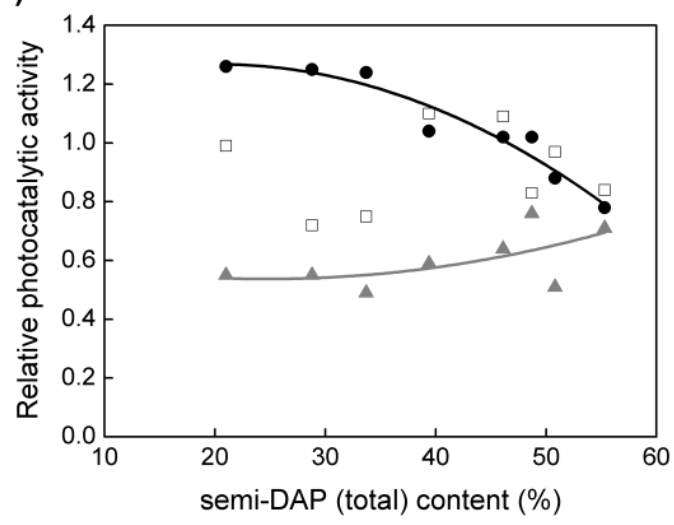

(b)

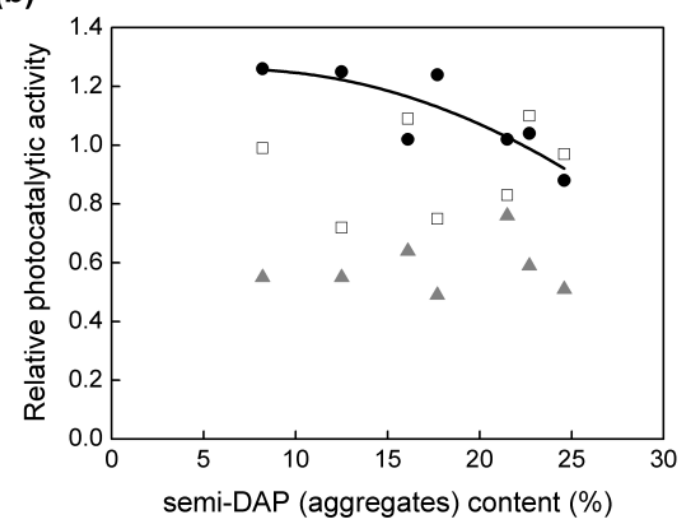

Figure 8. Correlation between photocatalytic activity $\left(\mathrm{CO}_{2}(\bullet), \mathrm{H}_{2}(\square)\right.$ and $\left.\mathrm{O}_{2}(\Delta)\right)$ and DAPs' morphology: (a) semi-DAPs and (b) semi-DAP (aggregated). Photocatalytic activities were standardized with reference to the photocatalytic activity of P25. 
Considering the photocatalytic activity of titania, it is impossible not to discuss one of the most active photocatalysts, that is, P25 (Degussa/Evonik/Nippon Aerosil). P25 is so famous that even commonly used as a standard [12,43-45]. Various reasons for its activity have been proposed, including (i) presence of impurities working as scavengers of charge carriers, and thus inhibiting charge carriers' recombination, for example, $\mathrm{Fe}^{3+}$ [46], (ii) presence of amorphous titania, participating in the charge carriers' migration [47], (iii) large content of adsorbed water and/or hydroxyl groups on titania surface [48-50], resulting in the efficient formation of hydroxyl radicals, (iv) co-existence of two titania polymorphs (anatase and rutile), causing either a longer lifetime of charge carriers via migration of charges between phases (the most frequently reported reason) [51,52] or being responsible for high activity in different reaction systems, that is, anatase and rutile in oxidation and reduction reactions, respectively $[43,44]$. It should be pointed out, that P25 does not possess the best physical properties and morphology (Figure 9) when compared to other titania photocatalysts. Indeed, even some DAPs products show much lower activity than that by P25, as shown in Figures 6 and 8 (all data below "1.0" as activity has been measured as relative to that by P25). At present, it is difficult to conclude if enhanced photocatalytic activity could be obtained for P25 with improved morphology/symmetry or not. It is possible that mixed-phase titania (anatase and rutile) of controlled morphology, e.g., faceted, could show the best photocatalytic performance among all other titania photocatalysts. However, nobody has investigated this aspect up to our knowledge yet.

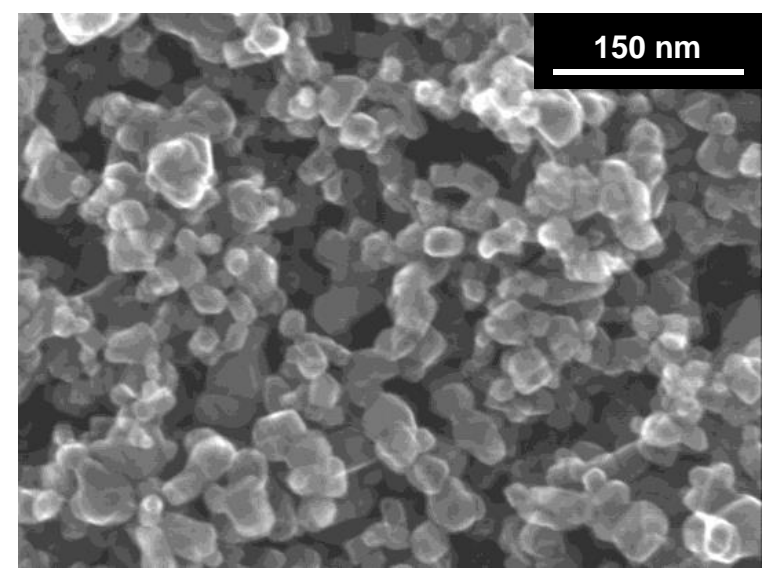

Figure 9. SEM image of P25 photocatalyst.

Of course, there are different examples of photocatalysts with non-symmetric morphology and improved photocatalytic performance. For example, "core@shell" $\mathrm{Cu}_{\mathrm{x}} \mathrm{O} @ \mathrm{TiO}_{2}$ (porous and non-symmetric structure), prepared by microemulsion method, has shown high photocatalytic stability thanks to the morphology, that is, hindering of copper dissolution (photo-corrosion) by protective titania shell, in contrast to unstable $\mathrm{Cu}_{2} \mathrm{O} / \mathrm{TiO}_{2}$ photocatalysts without core@shell morphology [53]. However, due to the lack of reference samples (symmetric $\mathrm{Cu}_{\mathrm{x}} \mathrm{O} @ \mathrm{TiO}_{2}$ ), it is impossible to exclude the symmetry/asymmetry importance in this (and many others) study.

\subsection{Plasmonic Photocatalysts}

Modified titania photocatalysts with deposits of noble metals for photocatalytic activity under visible-light (vis) irradiation, that is, plasmonic photocatalysts, are also discussed in the aspect of morphology and/or symmetry. Interestingly, it has been found that large rutile modified with gold NPs of different sizes and shapes (spherical and rod-like) has exhibited much higher vis activity than fine anatase modified with small and spherical gold NPs [54,55]. Although titania samples are highly asymmetric (commercial titania samples), more symmetric gold deposits (many spherical NPs) have been observed in the case of less active samples. It has been proposed that higher polydispersity in gold deposits results 
in broader plasmon peak, and thus more efficient light harvesting. Accordingly, it might be concluded that the less the symmetry in the sample is, the higher is the photocatalytic activity. However, it should be pointed out that since commercial titania samples have been taken, the influence of impurities, defects, and unclarified morphology should not be excluded. Therefore, faceted titania samples (OAPs and DAPs) have also been tested. Interestingly, much different vis activity has been observed for the samples that differed only by the morphology of gold deposits (same titania). In the case of OAPs-based samples, it has been found that the most active samples (Figure 10b and black curve in Figure 10c) are characterized by the most polydisperse gold NPs (and obviously lower symmetry) [56].
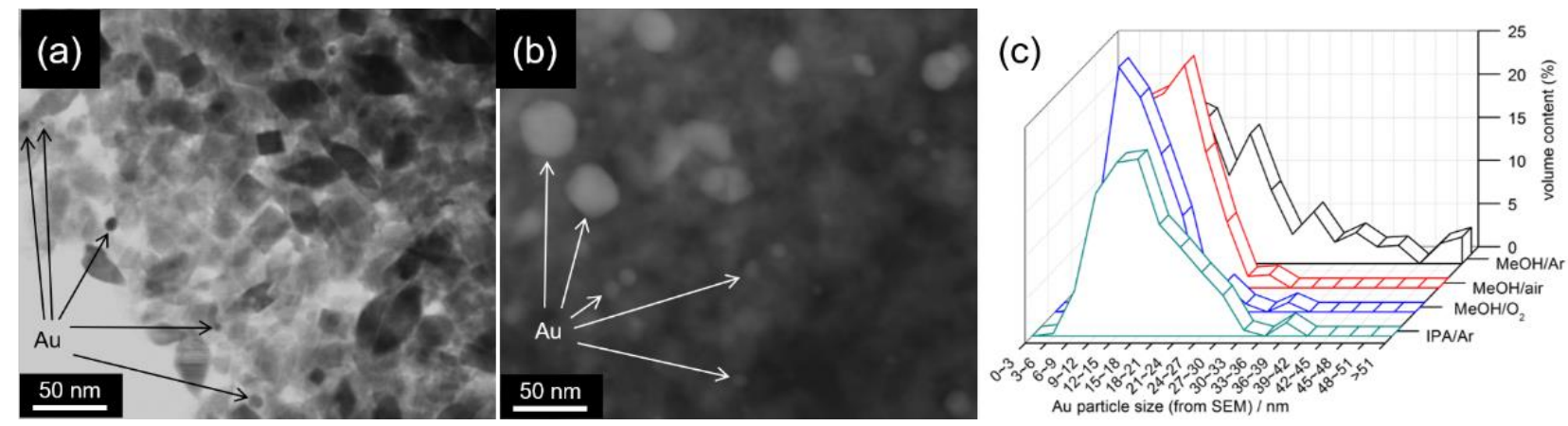

Figure 10. (a,b) STEM images of OAPs modified with gold NPs by photodeposition method: (a) smaller and more uniform gold NPs prepared in the initial presence of oxygen in the system $\left(\mathrm{MeOH} / \mathrm{O}_{2}\right) ;(\mathbf{b})$ larger and more nonuniform gold NPs prepared in the absence of oxygen in the system (MeOH/Ar); (c) distribution of gold NPs' size for OAPs-based samples prepared during photodeposition under different conditions: IPA-2-propanol, $\mathrm{MeOH}-m e t h a n o l$. Adapted with permission from [56]. Copyright 2017, Creative Commons Attribution License.

Next, the DAP-based sample was modified with gold NPs (Figure 11a), and though the more polydisperse gold NPs have been obtained, the worst vis activity has been obtained among both faceted and commercial titania samples, as shown in Figure 11b [57]. It should be pointed out that in contrast, Au/OAPs show the highest activity among all tested samples, being similar to that of rutile-based commercial samples with the best photoabsorption properties (the broadest plasmon peak). It has been proposed that shallow ETs are responsible for the high vis activity of Au/OAPs, that is, fast "hot" electron transfer via ETs (Figure 11c). Therefore, it might be concluded that symmetry is not so important for the vis response of plasmonic photocatalysts as both faceted titania samples are highly symmetric and gold NPs in both samples are polydisperse. In contrast, the morphology seems to be the key factors, as suggested from the proposed mechanism of vis activity (Figure 11c,d), where fast charge carriers' recombination is expected in Au/DAPs due to electron migration to $\{101\}$ facets.

Finally, another morphology of plasmonic photocatalysts was considered inverse opal titania (IOT) photonic crystals (PCs) with gold NP incorporated in each void space [58]. Inverse opal PC is a structure with periodic unit cells that give rise to the photonic band gap $(\mathrm{PBG})$, preventing light from propagating in certain directions with specified frequencies. According to the dispersion relation towards the bandgap, the group velocity of light in photonic crystals depends on the slop of the band. Near the PBG the group velocity of light reduces even to zero. Accordingly, this phenomenon is called "slow-photon" effect, which can extend the path length of light, and enhance the light-harvesting efficiency of materials. There are various studies showing that perfect morphology and thus symmetry are crucial to obtain good quality of PCs. For example, the insertion of different fractions/sizes of guest spheres into the opal template or mechanical destruction of IOT has resulted in a significant decrease in photocatalytic activity [59-61]. However, again both morphology and symmetry have been destroyed, and thus it is difficult to judge which of them is more important. In our recent study, gold-incorporated IOT PCs have been prepared, 
in which the same contents and properties (size) of gold NPs have been kept [58]. The samples differ only by the void diameter, and thus PBG wavelengths. Interestingly, only the samples with PBG wavelength edges overlapping with photoabsorption properties of either gold (plasmon resonance wavelength) or titania have shown significant enhancement of photocatalytic activity, that is, via efficient light-harvesting ("slow-photon" effect), as shown in Figure 12. Like other studies, the destruction of PCs structure by grinding has resulted in activity decrease, confirming that symmetry/morphology is important for photonic/photocatalytic properties. Accordingly, thought perfect symmetry is important to obtain PCs (from symmetric Au NPs via $\mathrm{Au} @ \mathrm{SiO}_{2}$ core@shell to $\mathrm{Au} @ \mathrm{TiO}_{2}$ ), it seems that symmetry does not govern photocatalytic activity since all Au@IOT samples have been symmetric but only diameter of void space, i.e., morphology, controls the overall photocatalytic activity.
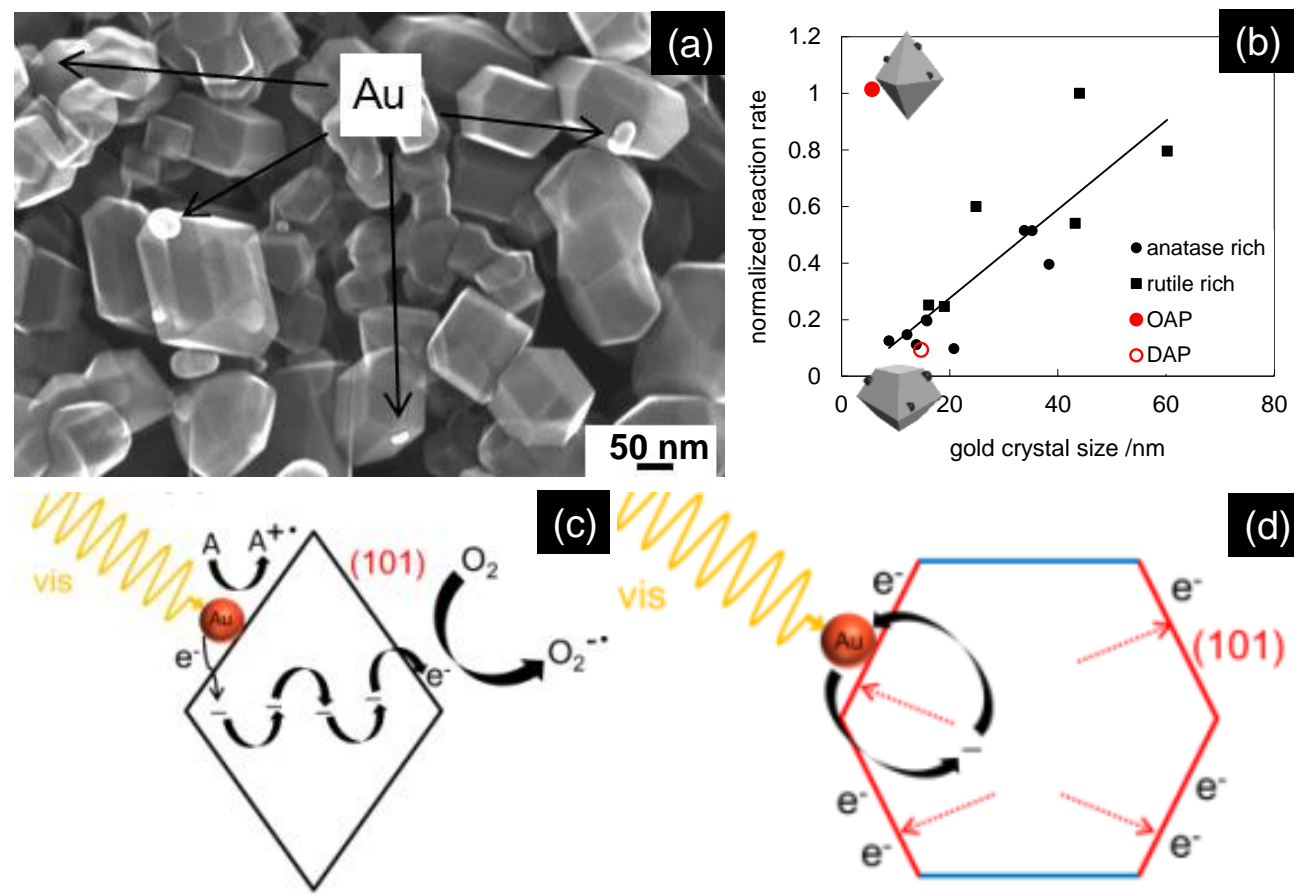

Figure 11. (a) SEM image of DAPs modified with gold NPs; (b) vis activity for 2-propanol oxidation for gold-modified titania: faceted samples in comparison to commercial samples; (c,d) proposed mechanism of vis response on gold-modified faceted titania: (c) Au/OAPs and (d) Au/DAPs. Adapted with permission from [57]. Copyright 2018, Creative Commons Attribution License. 


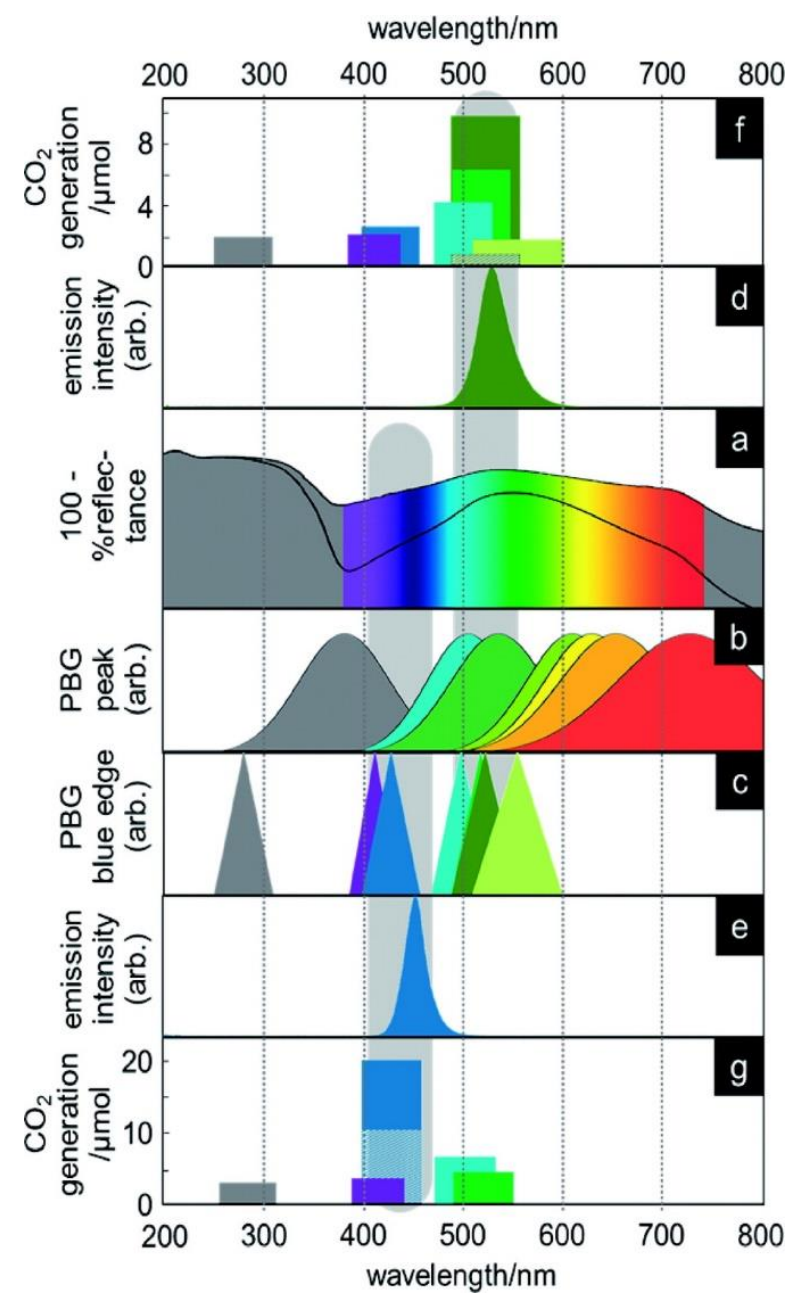

Figure 12. Matching of photoabsorption properties with resultant photocatalytic activities for AuNP@IOT samples with different nanovoid diameters: (a) representative DRS spectra of Au-NP@IOT with Au NP of $44 \mathrm{~nm}$ (upper) and $30 \mathrm{~nm}$ (below); (b) PBG peak for Au-NP@IOT samples with nanovoid $150 \mathrm{~nm}$ (grey) $200 \mathrm{~nm}$ (light blue) $215 \mathrm{~nm}$ (green) $240 \mathrm{~nm}$ (light green) $250 \mathrm{~nm}$ (yellow) $270 \mathrm{~nm}$ (orange) and $290 \mathrm{~nm}$ (red); (c) PBG blue-edge wavelengths for Au-NP@IOT samples with average nanovoid of $150 \mathrm{~nm}$ (grey) $200 \mathrm{~nm}$ (purple) $215 \mathrm{~nm}$ (blue) $240 \mathrm{~nm}$ (sky blue) $250 \mathrm{~nm}$ (green) $270 \mathrm{~nm}$ (darker green) and $290 \mathrm{~nm}$ (lime); (d,e) LED emission spectra of $530 \mathrm{~nm}$ and $450 \mathrm{~nm}$, respectively; $(\mathbf{f}, \mathbf{g}) \mathrm{CO}_{2}$ generation by Au-NP@IOT samples with bare IOT (shaded) (same colors as in (c)). Reprinted with permission from [58]. Copyright 2021, Creative Commons Attribution License.

\section{Conclusions}

As already well-known, the morphology of photocatalysts is a crucial and important factor influencing photocatalytic activity. Although in many cases highly active photocatalysts are symmetric, for example, faceted and IOT PCs, it is thought that the symmetry does not control the photocatalytic performance. In contrast, a slight change in the morphology (keeping the same asymmetric or symmetric properties) might result in a significant change in the photocatalytic activity. Accordingly, it has been concluded that in the contrast to the morphology, the symmetry of photocatalysts does not control the photocatalytic performance in heterogeneous photocatalysis. However, an additional study taking into consideration the co-existence of different symmetrical forms of faceted particles (e.g., DAPs with mounds) is required.

Of course, one cannot exclude the possibility that symmetry might control the photocatalytic activity, for example, in the case of special structures such as Janus particles and photocatalysts applied at particular conditions (e.g., at the phase boundary), but based on 
data presented here, the direct correlation between the symmetry and the photocatalytic activity could not be found.

Author Contributions: Conceptualization, E.K.; methodology, M.J. and B.O.; validation, M.J. and E.K.; investigation, E.K., M.J., Z.W., A.N. and K.W.; literature review, M.J., T.R.M., L.W. and E.K.; resources, E.K. and B.O.; writing—original draft preparation, M.J. and E.K.; writing—review and editing, all authors; visualization, E.K., M.J., Z.W. and K.W.; funding acquisition, E.K. and B.O. All authors have read and agreed to the published version of the manuscript.

Funding: This research was funded by the National Natural Science Foundation of China (NSFC) (51802087), the Natural Science Foundation of the Hubei province of China (2019CFB524), "YugoSohatsu Kenkyu" for an Integrated Research Consortium on Chemical Sciences (IRCCS) project from the Ministry of Education and Culture, Sport, Science and Technology-Japan (MEXT), and the Ministry of Education and Science of Poland.

Data Availability Statement: The data presented in this study are available on request from the corresponding author.

Acknowledgments: E.K. would like to thank T. Nakano (Institute for Catalysis, Hokkaido University) for inspiration of this paper on the symmetry in heterogeneous photocatalysis.

Conflicts of Interest: The authors declare no conflict of interest.

\section{References}

1. Etacheri, V.; Di Valentin, C.; Schneider, J.; Bahnemann, D.; Pillai, S.C. Visible-light activation of TiO 2 photocatalysts: Advances in theory and experiments. J. Photochem. Photobiol. C 2015, 25, 1-29. [CrossRef]

2. Nakata, K.; Fujishima, A. $\mathrm{TiO}_{2}$ photocatalysis: Design and applications. J. Photochem. Photobiol. C 2012, 13, 169-189. [CrossRef]

3. Chen, S.S.; Qi, Y.; Hisatomi, T.; Ding, Q.; Asai, T.; Li, Z.; Ma, S.S.K.; Zhang, F.X.; Domen, K.; Li, C. Efficient Visible-Light-Driven Z-Scheme Overall Water Splitting Using a $\mathrm{MgTa}_{2} \mathrm{O}_{6}-\mathrm{xNy} / \mathrm{TaON}$ Heterostructure Photocatalyst for $\mathrm{H}_{2}$ Evolution. Angew. Chem. Int. Ed. 2015, 54, 8498-8501. [CrossRef]

4. Suzuki, T.M.; Takayama, T.; Sato, S.; Iwase, A.; Kudo, A.; Morikawa, T. Enhancement of $\mathrm{CO}_{2}$ reduction activity under visible light irradiation over Zn-based metal sulfides by combination with Ru-complex catalysts. Appl. Catal. B-Environ. 2018, 224, 572-578. [CrossRef]

5. Abe, R.; Shinmei, K.; Koumura, N.; Hara, K.; Ohtani, B. Visible-Light-Induced Water Splitting Based on Two-Step Photoexcitation between Dye-Sensitized Layered Niobate and Tungsten Oxide Photocatalysts in the Presence of a Triiodide/Iodide Shuttle Redox Mediator. J. Am. Chem Soc. 2013, 135, 16872-16884. [CrossRef]

6. Abe, R. Recent progress on photocatalytic and photoelectrochemical water splitting under visible light irradiation. J. Photochem. Photobiol. C 2010, 11, 179-209. [CrossRef]

7. Ghosh, S.; Kouame, N.A.; Ramos, L.; Remita, S.; Dazzi, A.; Deniset-Besseau, A.; Beaunier, P.; Goubard, F.; Aubert, P.H.; Remita, H. Conducting polymer nanostructures for photocatalysis under visible light. Nat. Mater. 2015, 14, 505-511. [CrossRef] [PubMed]

8. Wu, J.-J.; Yu, C.-C. Aligned $\mathrm{TiO}_{2}$ Nanorods and Nanowalls. J. Phys. Chem. B 2004, 108, 3377-3379. [CrossRef]

9. Yang, H.G.; Sun, C.H.; Qiao, S.Z.; Zou, J.; Liu, G.; Smith, S.C.; Cheng, H.M.; Lu, G.Q. Anatase TiO 2 single crystals with a large percentage of reactive facets. Nature 2008, 453, 638-641. [CrossRef]

10. Kowalski, D.; Kim, D.; Schmuki, P. $\mathrm{TiO}_{2}$ nanotubes, nanochannels and mesosponge: Self-organized formation and applications. Nano Today 2013, 8, 235-264. [CrossRef]

11. Ohno, T.; Sarukawa, K.; Matsumura, M. Crystal faces of rutile and anatase $\mathrm{TiO}_{2}$ particles and their roles in photocatalytic reactions. New J. Chem. 2002, 26, 1167-1170. [CrossRef]

12. Wang, K.L.; Janczarek, M.; Wei, Z.S.; Raja-Mogan, T.; Endo-Kimura, M.; Khedr, T.M.; Ohtani, B.; Kowalska, E. Morphology-and crystalline composition-governed activity of titania-based photocatalysts: Overview and perspective. Catalysts 2019, 9, 1054. [CrossRef]

13. Selloni, A. Crystal growth-Anatase shows its reactive side. Nat. Mater. 2008, 7, 613-615. [CrossRef] [PubMed]

14. Pan, J.; Liu, G.; Lu, G.Q.; Cheng, H.-M. On the True Photoreactivity Order of $\{001\}$, $\{010\}$, and $\{101\}$ Facets of Anatase TiO 2 Crystals. Angew. Chem. Int. Ed. 2011, 50, 2133-2137. [CrossRef] [PubMed]

15. Liu, G.; Yu, J.C.; Lu, G.Q.; Cheng, H.M. Crystal facet engineering of semiconductor photocatalysts: Motivations, advances and unique properties. Chem. Commun. 2011, 47, 6763-6783. [CrossRef]

16. Lovette, M.A.; Browning, A.R.; Griffin, D.W.; Sizemore, J.P.; Snyder, R.C.; Doherty, M.F. Crystal Shape Engineering. Ind. Eng. Chem. Res. 2008, 47, 9812-9833. [CrossRef]

17. Tachikawa, T.; Yamashita, S.; Majima, T. Evidence for Crystal-Face-Dependent $\mathrm{TiO}_{2}$ Photocatalysis from Single-Molecule Imaging and Kinetic Analysis. J. Am. Chem. Soc. 2011, 133, 7197-7204. [CrossRef] 
18. Wei, Z.; Kowalska, E.; Verrett, J.; Colbeau-Justin, C.; Remita, H.; Ohtani, B. Morphology-dependent photocatalytic activity of octahedral anatase particles prepared by ultrasonication-hydrothermal reaction of titanates. Nanoscale 2015, 7, 12392-12404. [CrossRef]

19. Wei, Z.S.; Kowalska, E.; Ohtani, B. Enhanced Photocatalytic Activity by Particle Morphology: Preparation, Characterization, and Photocatalytic Activities of Octahedral Anatase Titania Particles. Chem. Lett. 2014, 43, 346-348. [CrossRef]

20. Janczarek, M.; Kowalska, E.; Ohtani, B. Decahedral-shaped anatase titania photocatalyst particles: Synthesis in a newly developed coaxial-flow gas-phase reactor. Chem. Eng. J. 2016, 289, 502-512. [CrossRef]

21. Amano, F.; Prieto-Mahaney, O.O.; Terada, Y.; Yasumoto, T.; Shibayama, T.; Ohtani, B. Decahedral single-crystalline particles of anatase titanium(IV) oxide with high photocatalytic activity. Chem. Mater. 2009, 21, 2601-2603. [CrossRef]

22. Yang, H.G.; Liu, G.; Qiao, S.Z.; Sun, C.H.; Jin, Y.G.; Smith, S.C.; Zou, J.; Cheng, H.M.; Lu, G.Q. Solvothermal Synthesis and Photoreactivity of Anatase $\mathrm{TiO}_{2}$ Nanosheets with Dominant $\{001\}$ Facets. J. Am. Chem. Soc. 2009, 131, 4078-4083. [CrossRef] [PubMed]

23. Yang, W.; Li, M.; Pan, K.; Guo, L.; Wu, J.; Li, Z.; Yang, F.; Lin, K.; Zhou, W. Surface engineering of mesoporous anatase titanium dioxide nanotubes for rapid spatial charge separation on horizontal-vertical dimensions and efficient solar-driven photocatalytic hydrogen evolution. J. Colloid Interface Sci. 2021, 586, 75-83. [CrossRef] [PubMed]

24. Bian, Z.F.; Tachikawa, T.; Zhang, P.; Fujitsuka, M.; Majima, T. Au/ $\mathrm{TiO}_{2}$ Superstructure-Based Plasmonic Photocatalysts Exhibiting Efficient Charge Separation and Unprecedented Activity. J. Am. Chem. Soc. 2014, 136, 458-465. [CrossRef] [PubMed]

25. Cui, X.; Wang, Y.; Jiang, G.; Zhao, Z.; Xu, C.; Wei, Y.; Duan, A.; Liu, J.; Gao, J. A photonic crystal-based CdS-Au-WO 3 heterostructure for efficient visible-light photocatalytic hydrogen and oxygen evolution. RSC Adv. 2014, 4, 15689-15694. [CrossRef]

26. Sordello, F.; Duca, C.; Maurino, V.; Minero, C. Photocatalytic metamaterials: $\mathrm{TiO}_{2}$ inverse opals. Chem. Commun. 2011, 47, 6147-6149. [CrossRef]

27. Araiedh, F.; Ducos, F.; Houas, A.; Chaoui, N. Photodegradation mode of stearic acid crystal on heterogeneous anatase/amorphous titania films observed by differential interference contrast microscopy. Appl. Catal. B-Environ. 2016, 187, 350-356. [CrossRef]

28. Luo, Y.; Geng, S.H.; Dube, L.; Zhao, J. Tuning the Valency of Heterogeneous Au-Silica Nanostructure via Controlled Ostwald Ripening Process. J. Phys. Chem. C 2018, 122, 18077-18085. [CrossRef]

29. Li, K.X.; Huang, Y.; Yan, L.S.; Dai, Y.H.; Xue, K.P.; Guo, H.Q.; Huang, Z.M.; Xiong, J.J. Simulated sunlight photodegradation of aqueous atrazine and rhodamine B catalyzed by the ordered mesoporous graphene-titania/silica composite material. Catal. Commun. 2012, 18, 16-20. [CrossRef]

30. Barmparis, G.D.; Kopidakis, G.; Remediakis, I.N. Shape-Dependent Single-Electron Levels for Au Nanoparticles. Materials 2016, 9, 301. [CrossRef]

31. Zhang, T.T.; Zhao, K.; Yu, J.G.; Jin, J.; Qi, Y.; Li, H.Q.; Hou, X.J.; Liu, G. Photocatalytic water splitting for hydrogen generation on cubic, orthorhombic, and tetragonal $\mathrm{KNbO}_{3}$ microcubes. Nanoscale 2013, 5, 8375-8383. [CrossRef] [PubMed]

32. King, N.; Boltersdorf, J.; Maggard, P.A.; Wong-Ng, W. Polymorphism and Structural Distortions of Mixed-Metal Oxide Photocatalysts Constructed with alpha-U3O8 Types of Layers. Crystals 2017, 7, 145. [CrossRef]

33. Huang, Z.Q.; Gong, J.L.; Nie, Z.H. Symmetry-Breaking Synthesis of Multicomponent Nanoparticles. Acc. Chem. Res. 2019, 52, 1125-1133. [CrossRef]

34. Murakami, N.; Mahaney, O.O.P.; Torimoto, T.; Ohtani, B. Photoacoustic spectroscopic analysis of photoinduced change in absorption of titanium(IV) oxide photocatalyst powders: A novel feasible technique for measurement of defect density. Chem. Phys. Lett. 2006, 426, 204-208. [CrossRef]

35. Nitta, A.; Takase, M.; Takashima, M.; Murakamid, N.; Ohtani, B. A fingerprint of metal-oxide powders: Energy-resolved distribution of electron traps. Chem. Commun. 2016, 52, 12096-12099. [CrossRef]

36. Amano, F.; Yasumoto, T.; Prieto-Mahaney, O.O.; Uchida, S.; Shibayama, T.; Terada, Y.; Ohtani, B. Highly active titania photocatalyst particles of controlled crystal phase, size, and polyhedral shapes. Top. Catal. 2010, 53, 455-461. [CrossRef]

37. Murakami, N.; Kurihara, Y.; Tsubota, T.; Ohno, T. Shape-Controlled Anatase Titanium(IV) Oxide Particles Prepared by Hydrothermal Treatment of Peroxo Titanic Acid in the Presence of Polyvinyl Alcohol. J. Phys. Chem. C 2009, 113, 3062-3069. [CrossRef]

38. Taguchi, T.S.Y.; Sarukawa, K.; Ohno, T.; Matsumura, M. Formation of new crystal faces on $\mathrm{TiO}_{2}$ particles by treatment with aqueous HF solution or hot sulfuric acid. New J. Chem. 2003, 27, 1304-1306. [CrossRef]

39. Amano, F.; Yasumoto, T.; Prieto-Mahaney, O.O.; Uchida, S.; Shibayama, T.; Ohtani, B. Photocatalytic activity of octahedral single-crystalline mesoparticles of anatase titanium(IV) oxide. Chem. Commun. 2009, 2311-2313. [CrossRef]

40. Kobayashi, K.; Takashima, M.; Takase, M.; Ohtani, B. Mechanistic Study on Facet-Dependent Deposition of Metal Nanoparticles on Decahedral-Shaped Anatase Titania Photocatalyst Particles. Catalysts 2018, 8, 542. [CrossRef]

41. Buchalska, M.; Kobielusz, M.; Matuszek, A.; Pacia, A.; Wojtyla, S.; Macyk, W. On Oxygen Activation at Rutile- and Anatase-TiO 2 . ACS Catal. 2015, 5, 7424-7431. [CrossRef]

42. Wei, Z.; Kowalska, E.; Ohtani, B. Influence of Post-Treatment Operations on Structural Properties and Photocatalytic Activity of Octahedral Anatase Titania Particles Prepared by an Ultrasonication-Hydrothermal Reaction. Molecules 2014, 19 , 19573-19587. [CrossRef] [PubMed] 
43. Ohtani, B.; Prieto-Mahaney, O.O.; Li, D.; Abe, R. What is Degussa (Evonik) P25? Crystalline composition analysis, reconstruction from isolated pure particles and photocatalytic activity test. J. Photochem. Photobiol. A Chem. 2010, 216, 179-182. [CrossRef]

44. Wang, K.L.; Wei, Z.S.; Ohtani, B.; Kowalska, E. Interparticle electron transfer in methanol dehydrogenation on platinum-loaded titania particles prepared from P25. Catal. Today 2018, 303, 327-333. [CrossRef]

45. Markowska-Szczupak, A.; Wang, K.L.; Rokicka, P.; Endo, M.; Wei, Z.S.; Ohtani, B.; Morawski, A.W.; Kowalska, E. The effect of anatase and rutile crystallites isolated from titania P25 photocatalyst on growth of selected mould fungi. J. Photochem. Photobiol. B 2015, 151, 54-62. [CrossRef]

46. Zhang, Z.; Wang, C.-C.; Zakaria, R.; Ying, J.Y. Role of Particle Size in Nanocrystalline $\mathrm{TiO}_{2}$-Based Photocatalysts. J. Phys. Chem. B 1998, 102, 10871-10878. [CrossRef]

47. Bickley, R.I.; Gonzalez-Carreno, T.; Lees, J.S.; Palmisano, L.; Tilley, R.J.D. A structural investigation of titanium dioxide photocatalysts. J. Solid State Chem. 1991, 92, 178-190. [CrossRef]

48. Kaewgun, S.; Nolph, C.A.; Lee, B.I.; Wang, L.-Q. Influence of hydroxyl contents on photocatalytic activities of polymorphic titania nanoparticles. Mater. Chem. Phys. 2009, 114, 439-445. [CrossRef]

49. Di Paola, A.; Bellardita, M.; Palmisano, L.; Barbieriková, Z.; Brezová, V. Influence of crystallinity and OH surface density on the photocatalytic activity of $\mathrm{TiO}_{2}$ powders. J. Photochem. Photobiol. A 2014, 273, 59-67. [CrossRef]

50. Deiana, C.; Fois, E.; Coluccia, S.; Martra, G. Surface Structure of $\mathrm{TiO}_{2}$ P25 Nanoparticles: Infrared Study of Hydroxy Groups on Coordinative Defect Sites. J. Phys. Chem. C 2010, 114, 21531-21538. [CrossRef]

51. Ohno, T.; Sarukawa, K.; Tokieda, K.; Matsumura, M. Morphology of a $\mathrm{TiO}_{2}$ photocatalyst (Degussa, P25) consisting of anatase and rutile crystalline phases. J. Catal. 2001, 203, 82-86. [CrossRef]

52. Hurum, D.C.; Agrios, A.G.; Gray, K.A.; Rajh, T.; Thurnauer, M.C. Explaining the Enhanced Photocatalytic Activity of Degussa P25 Mixed-Phase $\mathrm{TiO}_{2}$ Using EPR. J. Phys. Chem. B 2003, 107, 4545-4549. [CrossRef]

53. Wang, K.; Bielan, Z.; Endo-Kimura, M.; Janczarek, M.; Zhang, D.; Kowalski, D.; Zielińska-Jurek, A.; Markowska-Szczupak, A.; Ohtani, B.; Kowalska, E. On the mechanism of photocatalytic reactions on CuxO@ $\mathrm{TiO}_{2}$ core-shell photocatalysts. J. Mater. Chem. A 2021, 9, 10135-10145. [CrossRef]

54. Kowalska, E.; Mahaney, O.O.P.; Abe, R.; Ohtani, B. Visible-light-induced photocatalysis through surface plasmon excitation of gold on titania surfaces. Phys. Chem. Chem. Phys. 2010, 12, 2344-2355. [CrossRef] [PubMed]

55. Kowalska, E.; Abe, R.; Ohtani, B. Visible light-induced photocatalytic reaction of gold-modified titanium(IV) oxide particles: Action spectrum analysis. Chem. Commun. 2009, 2, 241-243. [CrossRef]

56. Wei, Z.; Rosa, L.; Wang, K.; Endo, M.; Juodkazi, S.; Ohtani, B.; Kowalska, E. Size-controlled gold nanoparticles on octahedral anatase particles as efficient plasmonic photocatalyst. Appl. Catal. B-Environ. 2017, 206, 393-405. [CrossRef]

57. Wei, Z.; Janczarek, M.; Endo, M.; Wang, K.L.; Balcytis, A.; Nitta, A.; Mendez-Medrano, M.G.; Colbeau-Justin, C.; Juodkazis, S.; Ohtani, B.; et al. Noble metal-modified faceted anatase titania photocatalysts: Octahedron versus decahedron. Appl Catal B-Environ. 2018, 237, 574-587. [CrossRef]

58. Raja-Mogan, T.; Lehoux, A.; Takashima, M.; Kowalska, E.; Ohtani, B. Slow photon-induced enhancement of photocatalytic activity of gold nanoparticle-incorporated titania in-verse opal. Chem. Lett. 2021, 50, 711-713. [CrossRef]

59. Chen, J.I.L.; von Freymann, G.; Kitaev, V.; Ozin, G.A. Effect of disorder on the optically amplified photocatalytic efficiency of titania inverse opals. J. Am. Chem. Soc. 2007, 129, 1196-1202. [CrossRef]

60. Chen, J.I.L.; von Freymann, G.; Choi, S.Y.; Kitaev, V.; Ozin, G.A. Amplified photochemistry with slow photons. Adv. Mater. 2006, 18, 1915-1919. [CrossRef]

61. Wu, M.; Li, Y.; Deng, Z.; Su, B.L. Three-Dimensionally Ordered Macroporous Titania with Structural and Photonic Effects for Enhanced Photocatalytic Efficiency. Chemsuschem 2011, 4, 1481-1488. [CrossRef] [PubMed] 